\title{
Optimal Demand Response of Smart Home with PV Generators
}

\author{
Chao-Rong Chen and Ming-Jen Lan \\ Electrical Engineering, National Taipei University of Technology, Taipei 106, Taiwan \\ Correspondence should be addressed to Chao-Rong Chen; crchen@ntut.edu.tw \\ Received 11 April 2014; Accepted 4 June 2014; Published 16 July 2014 \\ Academic Editor: Ching-Song Jwo
}

Copyright (C) 2014 C.-R. Chen and M.-J. Lan. This is an open access article distributed under the Creative Commons Attribution License, which permits unrestricted use, distribution, and reproduction in any medium, provided the original work is properly cited.

\begin{abstract}
Demand response (DR) is used mainly to help to schedule a customer's power utilization based on the electricity price that is announced by the power distribution company so that both demand and supply can optimally benefit. The work proposes a users' load model and the interior point method for optimal scheduling with elastic power utilization to minimize power price. The interior point method has the advantages of rapid convergence and robustness. Customers can not only use PV generators and battery sets as backup power sources, but also benefit from green energy. As revealed by the results herein, the use of elastic power utilization time intervals enables customers to pay less power price.
\end{abstract}

\section{Introduction}

With population growth and the continuously increasing demand for energy, international energy prices are rising substantially. Limited resources create a supply-demand imbalance in power systems. Therefore, power rationing in the summer is becoming increasingly possible, causing great inconvenience. Since most traditional industries have already given way to hi-tech industry, the stable supply of power to factories and production lines is important to businesses, and the enormous losses that are caused by power outages must be avoided. Hence, power companies must build more power plants and increase supply capacity, thus leading to increasing environmental pollution. Therefore, power companies are greatly concerned with stable and reliable power supply. The DR framework that is proposed in this study can be utilized to solve such problems.

Demand response (DR) is a method for dynamically adjusting the price of electricity that is used by power suppliers; it enables the power utilization characteristics of customers to be tuned, reducing the total power price and mitigating pressure on the power supply at peak times [1]. Advanced metering infrastructure (AMI) enables both demand and supply sides to transmit power utilization and power price information; the power distribution company (PDC) thus alters the power price according to supply or the priority of power facilities, causing customers to change their power consumption habits from normal power usage habits. Therefore, both the PDC and customers can reach great efficacy from such a framework. For customers, power utilization in the peak loading period can be shifted to other intervals when the price is lower to reduce the total power price [2-4]. Not only can the power utilization in the peak period be reduced, but also customers' hourly loading requirements can be precisely controlled, and PDC can respond quickly to changes in electricity price.

DR has become a popular issue in recent years, and several researchers have engaged in related research [5-10]. Various DR frameworks have been detailed [5]. To optimize the efficacy of DR, customers' power utilization curves were proposed to be divided into flat, average, and multiple-peak curves. Any changes (such as power price minimization) should not affect the quality of life of the customers. Dynamic pricing strategy and possible related system installation problems are addressed. Kirschen [6] proposed the use of electricity pricing flexibility to mitigate problems in the power market, but his method depends on massive active participation by customers to be optimally effective, limiting its implementation. The interruption contract method gives power companies more time to deal with emergent incidents concerning power generators and compensates customers when their power supply is interrupted. Ruiz et al. [7] 
proposed the virtual power plant (VPP) concept to schedule thermal appliances (air-conditioning, electric radiators). The proposed algorithm framework has been used in a power system in northern Spain, and simulations have revealed that optimal power utilization scheduling can be achieved in a particular control period, negotiation times between power companies and customers can be reduced, and demand and supply can be balanced. Black and Tyagi [8] noted that possible problems could arise when various pricing methods are used to perform scheduling for customers with large power utilization. In dynamic electricity pricing, customers reduce power utilization in higher price intervals, shifting it to lower price intervals. As a result, load predictions must be repeated and generators dispatched to cope with the additional power demand. If prices in the urgent peak periods are too great, then instant load transfer may occur, causing the subpeak phenomenon, which leads to instability of the generating system.

Palensky and Dietrich [9] divided demand management into areas concerned with energy efficiency, energy controllers, demand response, the distributed spinning reserve, demand shifting, and virtual power plants. They described in detail the advantages and features of various management approaches and proposed that DR be combined with other demand end management approaches to optimize efficacy. Chen et al. [10] proposed that to optimize the efficacy of DR, demand management, electricity price setting, and the prediction of power utilization and renewable energy generation must be properly performed. The main approaches to DR involve a power distribution company's negotiation of pricing with every customer and the customers' optimizing their power utilization scheduling according to the pricing that is announced by the power distribution company. However, Mohsenian-Rad et al. [11] proposed that such a negotiation may not optimize system power utilization, but the power utilization of each customer must be considered to optimize the efficacy of the DR strategy and to reduce the peak-toaverage ratio (PAR).

A high-quality, highly reliable power grid system with efficient use of energy-related equipment enables power companies to monitor precisely customers' real-time power utilization and control power supply/distribution. The establishment of such a system can be begun by promoting the installation of AMIs. AMIs include Smart Meters, communication systems, and a Meter Database Management System (MDMS); they can eliminate the need for traditional manual meter readings, provide information on user energy utilization, promote spontaneous energy saving, and reduce price.

Electricity pricing methods can be divided into CriticalPeak Pricing (CPP), Time-of-Use Pricing (TOU), and RealTime Pricing (RTP) methods [12]. RTP is more flexible than the other two methods because it allows prices to change hourly and therefore can reflect fuel cost and market pricing [13]. However, customers with high power utilization (such as companies and schools) can be overcome to optimize efficacy.

In recent years, several home appliance manufacturers, such as LG, Panasonic, and Samsung, have been actively promoting smart home appliances, which support the implementation of the DR strategy [14]. Smart home appliances usually receive power pricing information from suppliers in real time through a home energy management system (EMS), which automatically plans optimal hourly power utilization, enabling customers to have their appliances consume power in preferred intervals [15].

The literature includes several approaches to power utilization scheduling to minimize power price. The matter of metaheuristic algorithm [16] uses simulated annealing (SA), and the application of the concept of the "third party" to customer power utilization scheduling has been proposed. Since both power companies and customers have their own objectives, which are to minimize the power price and the operating cost of generators, a question arises regarding whether social benefit can be optimized given customers' optimization of power utilization scheduling and the power companies' equipment, manpower, and spanning cost. This study achieves these factors indirectly.

Particle swarm optimization (PSO) [17] is used to solve the scheduling problem for the power distribution system for household users, and the original cooperative particle swarm optimization (CPSO) is improved upon by the development of coevolutionary particle swarm optimization (CPSO). A random particle is added, so the original singular scheduling optimization can be expanded to multiple customers' scheduling optimization, and the efficacy of distribution end scheduling optimization can be improved. The Hybrid Genetic Algorithm [18] is adopted to solve the problem of scheduling multiple machines that operate in parallel in a factory. The weighting concept can be applied to reduce the cost to the factory, wasted energy, and polluting emissions.

Samadi et al. [19] and Li et al. [20] proposed the gradient concept. When dynamic pricing negotiation is performed, power usage is multiplied by a stepping variable to the negotiated prices to converge. The variable falls gradually as the negotiation time increases, so the problem that the power rate fails to converge stably can be solved.

Owing to the high efficiency of customers' power utilization, linear programming (LP) has been extensively discussed by researchers. Kurucz and Brandt [21] described direct loading control planning to reduce the power usage in the system peak period, and they conducted simulations of the usage of power by a lamp company in Florida. Kah-Hoe and Sheblé [22] noted that after power market control is removed, the loading control strategy that is directly based on benefits becomes more favored. Conejo et al. combined a simple LP algorithm [23] with EMS to enable customers to negotiate pricing with power distribution companies on an hourly basis, with the goal of optimizing the scheduling of power utilization and pricing. Simulation results demonstrate that the efficacy of customers' strategy can be optimized and their cost of energy minimized. The application of mixed integer linear programming [24] (MILP) to customer power utilization scheduling has been proposed. When a home energy controller is used to categorize home appliances, economical efficacy can be improved and PAR reduced.

In recent years, the proportion of power that has been generated from renewable resources has gradually increased. 
Output stabilization and predictability are serious issues. Increasing energy storage can reduce variations in the amplitude of the generated power, reduce power usage on-peak and off-peak, compensate for uncertainty in renewable power output, and improve the quality of the power supply. Energy storage systems in the grid can be loaded off-peak and power can be acquired from the grid for recharging. During the peak period, the energy storage equipment supplies the power, improving the system's power supply stability.

The batteries in an energy storage system are small in size, respond rapidly, and provide flexibility in capacity planning; they are therefore widely used. Lithium-iron phosphate $\left(\mathrm{LiFePO}_{4}\right)$ [25] batteries have a large power density, a long operating lifetime, and high safety. Hence, in this study, $\mathrm{LiFePO}_{4}$ batteries are used to optimize customers' power utilization scheduling.

Studies of DR and energy storage equipment have neglected important issues, which are addressed herein, as follows.

(1) A power distribution company may announce hourly electricity price, but electricity price information is not sufficient. This study provides a curve of electricity price as a function of total power usage by customers. This curve provides detailed power usage information for power utilization scheduling.

(2) The study of power utilization scheduling considers battery sets. Battery sets improve the reliability of the power supply, eliminating concern about power rationing, reducing the power rate, and solving the peak power usage problem.

\section{System Model}

The system model includes a power distribution company and customers with PV generators and AMI installed. The power distribution company summarizes its customers' total power usage and then purchases power in the market, which it sells to these customers. The selling price includes the costs of power generation, power transmission, and power distribution. The customers hourly total power usage is related to the electricity price and represented as a function of amount of loading. As the customers' power usage increases, electricity price will increase, and the loading curve is used to approximate the weighted hourly electricity price. Therefore, a curve of total electricity price as a function of power usage for $24 \mathrm{~h}$ can be plotted.

Power utilization is divided into inelastic and elastic utilization. For inelastic power utilization, such as refrigerators and electric water heaters, their use time is fixed; elastic power utilization refers to usage time that varies with electricity pricing, such as electric cars or handset batteries. In off-peak periods, batteries are recharged; in peak periods, they supply their own power. Customers can vary their elastic power use and battery charging and recharging times. The mathematical model of this study will be described below. The power distribution company alters electricity pricing in response to customers' power usage, and customers conduct power utilization scheduling according to the electricity price.
The control variables for optimizing customers' $24 \mathrm{~h}$ power utilization scheduling are elastic power usage and battery charging and recharging amount. Limiting conditions are power usage and battery-related use limits. The objective function is the minimization of customers' electricity price and cost of battery operating loss as follows:

$$
\min \sum_{t=1}^{t=24} p(t) \cdot(H(t)+q(t)+r(t))+D(r(t)),
$$

where $p(t)$ is the total power usage that is announced by the power distribution company, based on the electricity pricing curve at time $t . H(t)$ is customers' inelastic power usage used at time $t . q(t)$ is customers' elastic power usage at time t. $r(t)$ is customers' battery charge/recharge volume at time $t . D(\cdot)$ is cost to customers of using battery.

Constraints are as follows.

(1) The elastic power utilization limits are given by

$$
\begin{gathered}
q^{\min } \leq q(t) \leq \min \left(Q-H(t), q^{\max }\right), \quad t=1 \sim 24, \\
\sum_{t=1}^{t=24} q(t)=q^{\text {total }},
\end{gathered}
$$

where $Q$ is contracted capacity made available to customers by power distribution companies. $q^{\text {min }}$ is customers' hourly minimum elastic power usage limit. $q^{\max }$ is customers' hourly maximum elastic power usage limit. $q^{\text {total }}$ is customers' $24 \mathrm{~h}$ total elastic power usage limit.

(2) Equation (3) yields the total power usage limit:

$$
H(t)+q(t)+r(t) \leq Q, \quad t=1 \sim 24 .
$$

(3) Equation (4) specifies the limits on the battery charging and discharging:

$$
-r^{\min } \leq r(t) \leq r^{\max }, \quad t=1 \sim 24
$$

where $-r^{\min }$ is the battery discharging limit. $r^{\max }$ is the battery charging limit.

(4) Equation (5) presents the limits on the charge of a battery:

$$
\operatorname{SOC}^{\min } \leq \operatorname{SOC}(t) \leq \operatorname{SOC}^{\max }, \quad t=1 \sim 24,
$$

where SOC ${ }^{\mathrm{min}}$ is the lower bound on the charge of the battery. SOC ${ }^{\max }$ is the upper bound on the charge of the battery.

(5) Equation (6) provides the initial condition on charge of battery:

$$
\operatorname{SOC}(1)=\operatorname{SOC}^{\text {initial }}
$$

(6) Equation (7) provides the final change state of the battery:

$$
\operatorname{SOC}(25) \geq \operatorname{SOC}^{\text {initial }} \text {. }
$$


(7) Equation (8) provides the power usage efficiency of the battery:

$$
\eta=96.5 \%
$$

(8) Equation (9) gives the charge state as a function of batteries:

$$
\operatorname{SOC}(t+1)=\operatorname{SOC}(t)+r(t), \quad t=1 \sim 24 .
$$

(9) Equation (10) gives the cost of battery operation and electricity. The terms $\eta_{1}, \eta_{2}, \eta_{3}$, and $\delta$ are all constants:

$$
\begin{aligned}
D(\cdot)= & \eta_{1} \sum_{t \in T}(r(t))^{2}-\eta_{2} \sum_{t=1}^{T-1} r(t) r(t+1) \\
& +\eta_{3} \sum_{t \in T}\left(\min \left(\operatorname{SOC}(t)-\delta \cdot \operatorname{SOC}^{\mathrm{max}}, 0\right)\right)^{2} .
\end{aligned}
$$

\section{Methodology}

This section investigates the methods including the genetic algorithm and the interior point method. The section also elucidates how these methods are used to solve the customers' $24 \mathrm{~h}$ optimal power utilization scheduling problem.

The procedure for solving the customers' $24 \mathrm{~h}$ power utilization scheduling problem using the genetic algorithm [26] is shown below.

\subsection{Genetic Algorithm}

(1) Set parameters.

(a) Power distribution company: total power usage corresponding to given power pricing curve and $24 \mathrm{~h}$ electricity price weighted coefficient.

(b) Customers: the constant of (2) and (3).

(c) Customers' battery constant of (4)-(10).

(2) Customers perform power utilization scheduling based on electricity pricing weighted curve announced by power distribution company.

(3) Randomly generate initial population. Elastic power usage amount as control variable of customer's 24hour power scheduling.

(4) Find the fitness function value of (1).

(5) Determine whether the termination condition has been reached. If yes, present the customer's optimal 24-hour power usage schedule. If not, perform the next step.

(6) Based on the elitism rule, duplicate the parent chromosomes to the next generation.

(7) Based on the crossover rate, use roulette wheel selection to select chromosomes from the parent generation for duplication, crossover, and mutation.

(8) Treat the chromosomes that are generated in steps (6) and (7) as the new parent population, and return to step (4).
3.2. Interior Point Method. In 1984, Karmarkar [27] presented the primal-dual IPM (PDIPM), which is an algorithm for continued nonlinear planning. The theoretical basis of the interior point method includes three other important methods: the barrier function method of Fiacco \& McCormick is used to solve the problem under nonequality limiting conditions; the Lagrange equation is used to solve optimization problem of equality limiting conditions; Newton iterative method is used to solve a set of nonlinear equations without limiting conditions [28]. The application of the PDIPM to the customers' 24-hour power utilization scheduling problem will be described in detail below.

(1) Set parameters.

(2) Customers perform power utilization scheduling based on the electricity price weighted curve that is announced by the power distributing company.

(3) Determine whether the maximum number of iterations has been reached. If yes, present the customer's optimal 24-hour power usage schedule and stop. If not, perform step (4).

(4) Calculate the intercompensation gap, given by

$$
C_{\mathrm{Gap}}=\sum_{i=1}^{r}\left(l_{i} z_{i}-\mu_{i} \omega_{i}\right),
$$

where $l, \mu$ : slack variable; $z, \omega$ : Lagrange multiplier; and $r$ : constraint number.

(5) Determine whether the intercompensation gap is less than the tolerance. If so, present the customer's optimal 24-hour power usage schedule and stop. If not, perform step (6).

(6) Calculate the disturbance factor, given by

$$
u=\sigma \frac{C_{\mathrm{Gap}}}{2 r},
$$

where $\sigma$ : central parameter.

(7) Use the Lagrange function to infer and combine the objective function and constraints, and use the Newton method to transform to the disturbance KarushKuhn-Tucker (KKT) equation (15). The objective function is (1), and the constraints are (2)-(10). Control variables are elastic power usage and battery charge/discharge volume:

$$
\begin{gathered}
\Delta l=\nabla g(x)^{T} \Delta x+L_{z 0}, \\
\Delta \mu=-\left(\nabla g(x)^{T} \Delta x+L_{\omega 0}\right), \\
\Delta z=-L^{-1} Z \nabla g(x)^{T} \Delta x-L^{-1}\left(Z L_{z 0}+L_{l 0}\right), \\
\Delta \omega=U^{-1} W \nabla g(x)^{T} \Delta x+U^{-1}\left(W L_{\omega 0}-L_{\mu 0}\right), \\
{\left[\begin{array}{cc}
H(\cdot) & J(x)^{T} \\
J(x) & 0
\end{array}\right]\left[\begin{array}{c}
\Delta x \\
\Delta y
\end{array}\right]=-\left[\begin{array}{c}
\Psi(\cdot, u) \\
h(x)
\end{array}\right],}
\end{gathered}
$$


where

$$
\begin{aligned}
& H(\cdot)= H_{h}+H_{g} \\
&=\left(\nabla^{2} h(x) y+\nabla^{2} g(x)(z+\varpi)-\nabla^{2} f(x)\right) \\
&+g(x)\left(U^{-1} W-L^{-1} Z\right) \nabla g(x)^{T}, \\
& J(x)=\nabla h(x)^{T}, \\
& \Psi(\cdot, u)= \nabla h(x) y-\nabla f(x)+\nabla g(x) \\
& \times\left(U^{-1} W L_{\omega 0}-L^{-1} Z L_{z 0}-u\left(U^{-1}-L^{-1}\right) e\right), \\
& L_{x 0}=\left(\nabla^{2} h(x) y+\nabla^{2} g(x)(z+\omega)-\nabla^{2} f(x)\right) \Delta x \\
&+ \nabla h(x) \Delta y+\nabla g(x)(\Delta z+\Delta \omega), \\
& L_{y 0}=-\nabla h(x)^{T} \Delta x, \\
& L_{z 0}=-\nabla g(x)^{T} \Delta x-\Delta l, \\
& L_{\omega 0}=-\left(\nabla g(x)^{T} \Delta x+\Delta \mu\right), \\
& L_{l 0}=-(Z \Delta l+L \Delta z), \\
& L_{\mu 0}=-(W \Delta \mu+U \Delta \omega),
\end{aligned}
$$

where $\left(L_{x 0}, L_{y 0}, L_{l 0}, L_{\mu 0}, L_{z 0}, L_{\oplus 0}\right)$ is the residual disturbance KKT equation; $f(x)$ is the objective function; $h(x)$ is the equality constraint; $g(x)$ is the nonequality constraint; $(L, U, Z, W)$ is a diagonal matrix; $H_{h}$ is a Hessian matrix that comprises, or is composed of, or consists of the objective function and the equality and nonequality constraints; $H_{g}$ is the barrier matrix; $e$ is the unit matrix, and $y$ is the Lagrange index.

(8) Solve (13)-(15) for the slack variable between the Lagrange multiplier and the control variables.

(9) Solve the maximum step length among the original and dual space according to the following:

$\alpha_{p}=0.9995$

$$
\cdot \min \left\{\min _{i}\left(\frac{-l_{i}}{\Delta l_{i}}: \Delta l_{i}<0 ; \frac{-\mu_{i}}{\Delta \mu_{i}}: \Delta \mu_{i}<0\right), 1\right\},
$$

$\alpha_{D}=0.9995$

$$
\cdot \min \left\{\min _{i}\left(\frac{-z_{i}}{\Delta z_{i}}: \Delta z_{i}<0 ; \frac{-\varrho_{i}}{\Delta \varrho_{i}}: \Delta \varrho_{i}>0\right), 1\right\} .
$$

(10) Update original and dual variables using

$$
\begin{aligned}
& {\left[\begin{array}{l}
x \\
l \\
\mu
\end{array}\right]^{t+1}=\left[\begin{array}{c}
x \\
l \\
\mu
\end{array}\right]^{t}+\alpha_{p}\left[\begin{array}{c}
\Delta x \\
\Delta l \\
\Delta \mu
\end{array}\right]^{t},} \\
& {\left[\begin{array}{c}
y \\
z \\
\omega
\end{array}\right]^{t+1}=\left[\begin{array}{c}
y \\
z \\
\emptyset
\end{array}\right]^{t}+\alpha_{D}\left[\begin{array}{c}
\Delta y \\
\Delta z \\
\Delta \omega
\end{array}\right]^{t} .}
\end{aligned}
$$

(11) Return to step (3).

\section{Case Study}

This work includes the simulation of power utilization scheduling for a specific community, given total power usage in one day. The power distribution company announces 24 hour electricity prices and weighted coefficients through AMI to customers. Customers' power usage is composed of inelastic power, elastic power, $\mathrm{PV}$ generator prediction, and $\mathrm{LiFePO}_{4}$ battery.

The battery sets are backup power supply for increasing power supply reliability, rather than for power use scheduling, so the cost of setting up the battery is not considered; only the operating cost of the battery is considered.

The objection function is (1), which is used to compare schedules and electricity rates with and without the DR strategy which involves flexible power use based on electricity pricing. The details of scenarios are as follows.

(A) Customers' power use scheduling does not exploit the DR strategy.

(1) Hourly elastic power usages are all equal.

(2) Hourly total power usages are all equal.

(B) Customers' power use scheduling exploits the DR strategy.

(1) Battery is not installed.

(2) Battery is installed; operating cost is considered.

Initial data related to the customers' power use scheduling problem are presented below.

(A) Power distribution company.

(1) The curve for total power usage as a function of electricity pricing, plotted in Figure 1, which can be approximated as a cubic equation, given by

$$
p(x)=107 \times x^{3}-210 \times x^{2}+323 \times x+101,
$$

where $x$ is total power usage. $p(\cdot)$ is unit power price.

(2) 24-hour electricity pricing weighted coefficient shown in Figure 2.

(B) Customers.

(1) Hourly inelastic power usage, PV power generation as shown in Figure 3.

(2) Power use scheduling data presented in Table 1.

(3) Battery capacity and charging limits given in Table 2.

(4) Battery operating loss cost coefficient presented in Table 3.

(5) Genetic algorithm parameters presented in Table 4. 


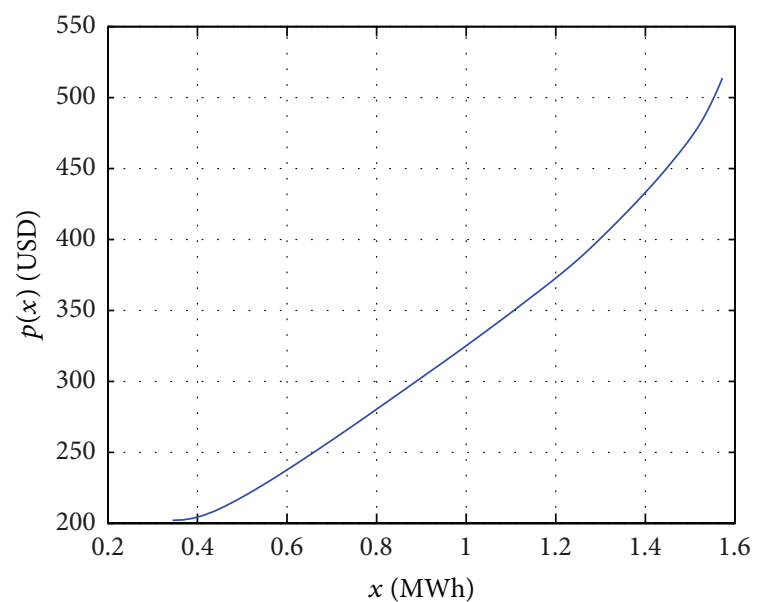

FIGURE 1: Curve of total power usage corresponding to electricity pricing.

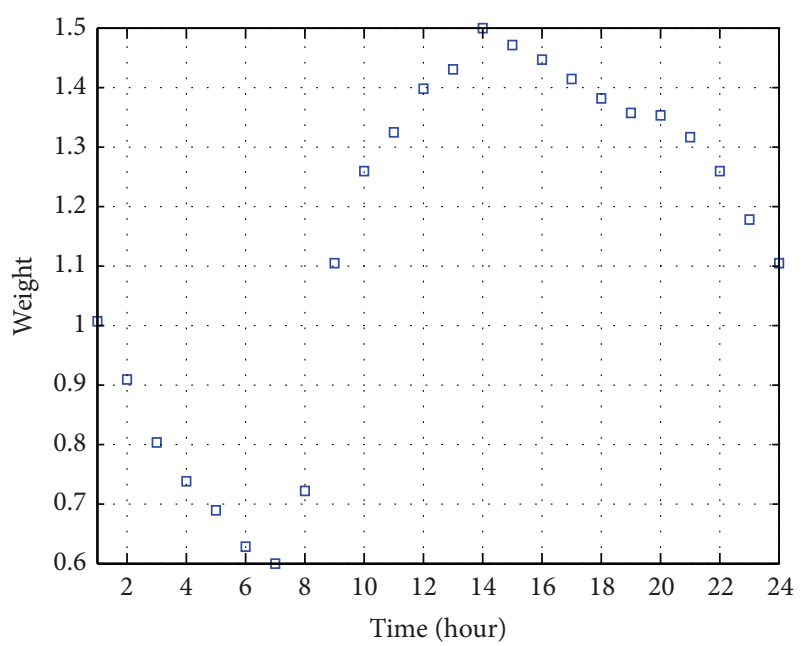

FIGURE 2: 24-hour electricity pricing weighted coefficient.

TABLE 1: Power use scheduling data.

\begin{tabular}{lccc}
\hline $\begin{array}{l}\text { Elastic electricity } \\
\text { lower bound } \\
(\mathrm{MW})\end{array}$ & $\begin{array}{c}\text { Elastic electricity } \\
\text { upper bound } \\
(\mathrm{MW})\end{array}$ & $\begin{array}{c}\text { Total electricity } \\
\text { lower bound } \\
\text { (MW) }\end{array}$ & $\begin{array}{c}\text { Contract } \\
\text { capacity } \\
\text { (MW) }\end{array}$ \\
\hline 0 & 0.36 & 7 & 1.2 \\
\hline
\end{tabular}

\section{Results}

5.1. DR Strategy Not Used. The benefit of changing power use habits is related to personal preferences, and to a factor that specifies whether customers will use a DR strategy to perform power use scheduling. If the inducement to change power use habits is not sufficient, then customers will not do so. A possible power use scheduling method of customers who do not use the DR strategy is as follows.

Figure 4 displays identical customers' hourly flexible power usage schedules. Since the hourly flexible power usages are identical, the total power usage and nonflexible power usage are related by a constant ratio. Figure 5 displays

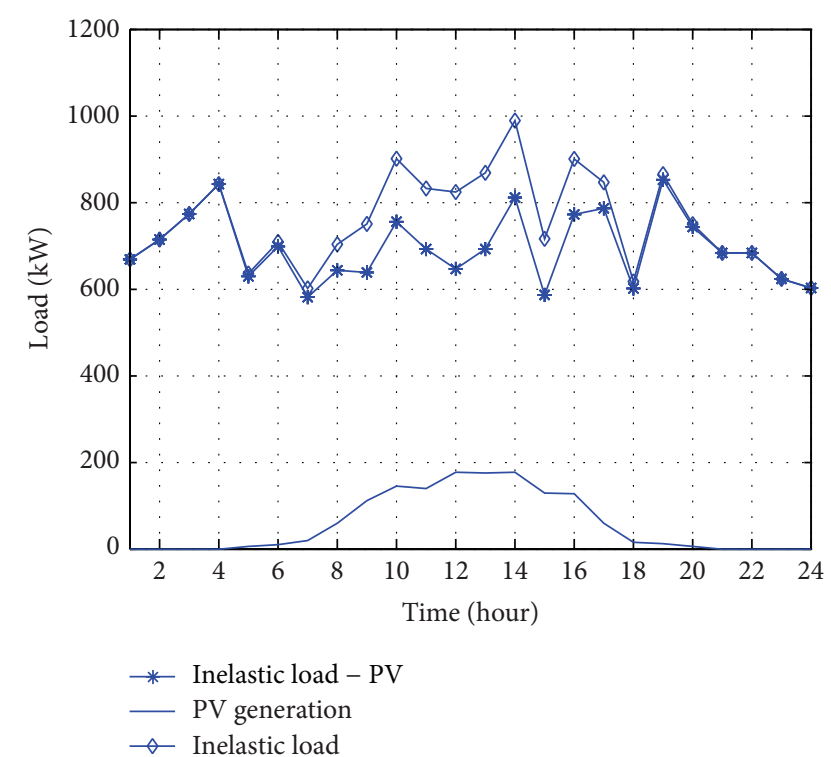

FIGURE 3: Hourly inelastic power usage and PV power generation.

TABLE 2: Battery set capacity and status limits.

\begin{tabular}{lccc}
\hline $\begin{array}{l}\text { Capacity } \\
(\mathrm{MWh})\end{array}$ & $\begin{array}{c}\text { State of charge } \\
\text { lower bound } \\
(\mathrm{MWh})\end{array}$ & $\begin{array}{c}\text { State of charge } \\
\text { upper bound } \\
(\mathrm{MWh})\end{array}$ & $\begin{array}{c}\text { Charge/Discharge } \\
\text { Limit } \\
(\mathrm{MW})\end{array}$ \\
\hline 0.6 & 0.18 & 0.42 & $-1.2 / 1.2$ \\
\hline
\end{tabular}

TABLE 3: Battery set capacity and status limits.

\begin{tabular}{lc}
\hline$\eta_{1}$ & $5 * 10^{-4}$ \\
$\eta_{2}$ & $4 * 10^{-4}$ \\
$\eta_{3}$ & 1 \\
$\delta$ & 0.2 \\
\hline
\end{tabular}

TABLE 4: Genetic algorithm parameter setting.

\begin{tabular}{lc}
\hline Population & 200 \\
Iteration & 3000 \\
Crossover rate & 1 \\
Mutation rate & 0.01 \\
Elite rate & 0.4 \\
\hline
\end{tabular}

identical customers' hourly total power usage schedules. The total nonflexible power usage and the flexible power usage have an inverse relationship.

5.2. DR Strategy Adopted. To reduce the cost of electricity, customers may adjust their power usage habits. Power use scheduling is simulated with and without an installed battery, and the battery operating cost is considered.

5.2.1. Battery Set Not Installed. Figures 6 and 7 display the results of using the IPM and GA to simulate customers' 24-hour power use scheduling without a battery. As shown in the diagram, in the period of a lower power price, 1 9 


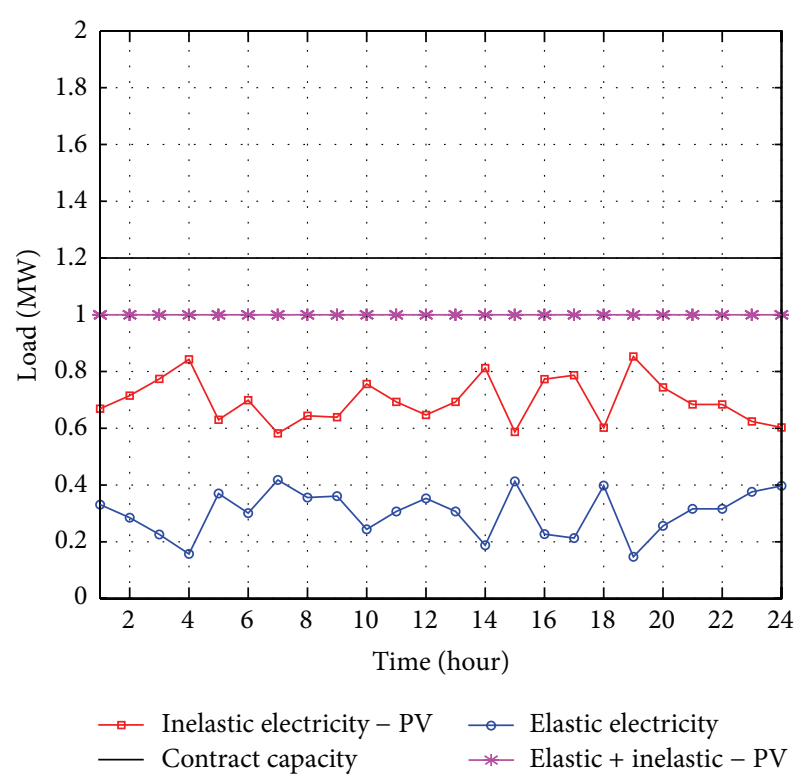

FIgURE 4: Customers' hourly total power usages are identical.

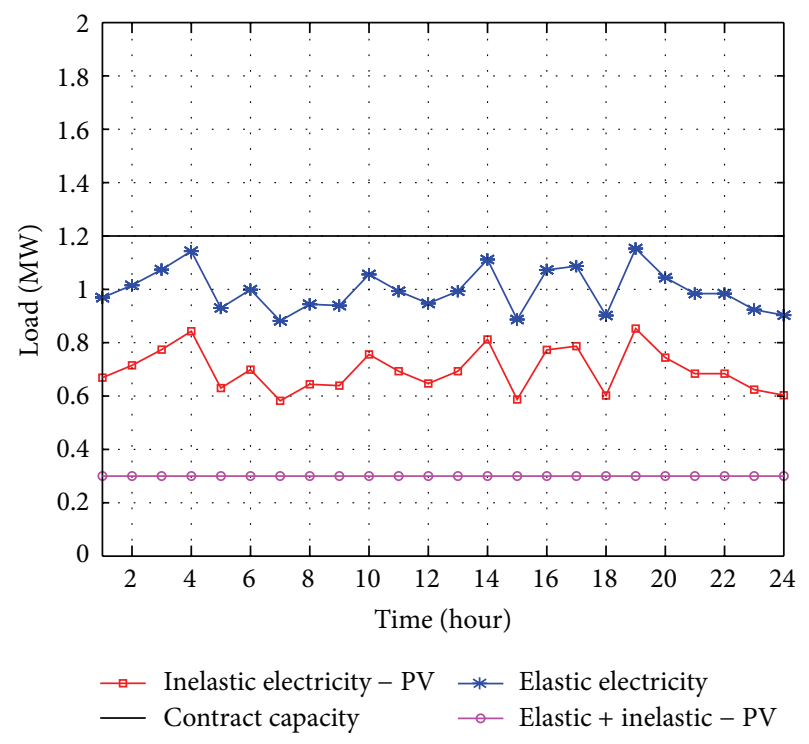

FIGURE 5: Customers' hourly elastic power usages are identical.

hours, customers use more flexible power; at times of higher electricity price, such as the 14th hour, customers do not use flexible power. The constraint on flexible power use causes customers to keep their total power use under the contracted capacity even in the period of lower price, such as the fourth hour, to avoid the extra power fee.

5.2.2. Battery Set Installed; Operating Loss Cost Considered. Figures 8 and 9 display results obtained using the interior point method and GA to simulate customers' $24 \mathrm{~h}$ power use scheduling with a battery set installed and operating loss cost considered. As shown in the diagram, in periods of lower electricity price, such as 1 9 hours, customers use more flexible power; in periods of higher electricity price,

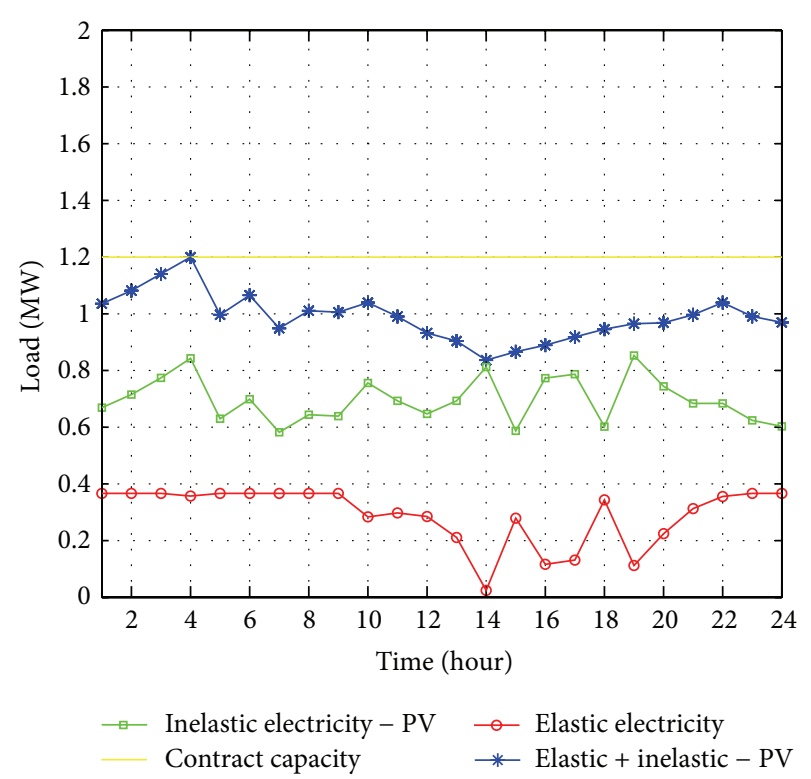

FIGURE 6: With IPM to simulate customers' power use scheduling without battery set installed.

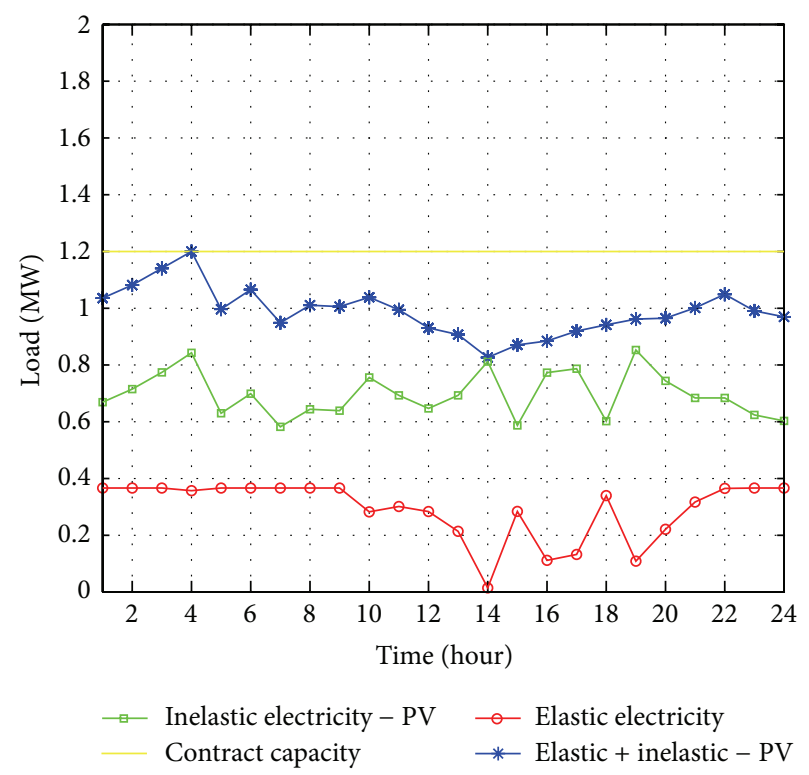

FIGURE 7: With GA to simulate customers' power use scheduling without battery set installed.

such in the 14th hour, customers use less or no power. In the 5 8 hours' period, the batteries are recharging because the power price is low, for later use in supplying power in a period of higher electricity price; at 10 15 hours, customers use batteries to supply power because the price is high. Moreover, since the operating loss cost of the batteries is considered, an excessive battery recharge volume could increase the cost, so the scope for using the battery for the purpose of reducing the cost of power is not large. The constraint on flexible power use may make customers keep their total power usage under 
TABLE 5: Result of comparing the methods.

\begin{tabular}{|c|c|c|c|c|}
\hline & Scenarios & Method & $\begin{array}{l}\text { Cost } \\
\text { (USD) }\end{array}$ & $\begin{array}{l}\text { Time } \\
(\mathrm{sec})\end{array}$ \\
\hline \multirow{2}{*}{ No DR } & Elastic power usages are identical & - & $8,765.5$ & - \\
\hline & total power usages are identical & - & $8,725.9$ & - \\
\hline \multirow{4}{*}{ DR } & \multirow{2}{*}{ Without battery pack } & GA & $8,658.91$ & 490.3 \\
\hline & & IPM & $8,659.2$ & 1.4 \\
\hline & \multirow{2}{*}{ With battery pack and considering the cost of operating loss } & GA & $8,637.79$ & 850.2 \\
\hline & & IPM & $8,635.1$ & 29.35 \\
\hline
\end{tabular}

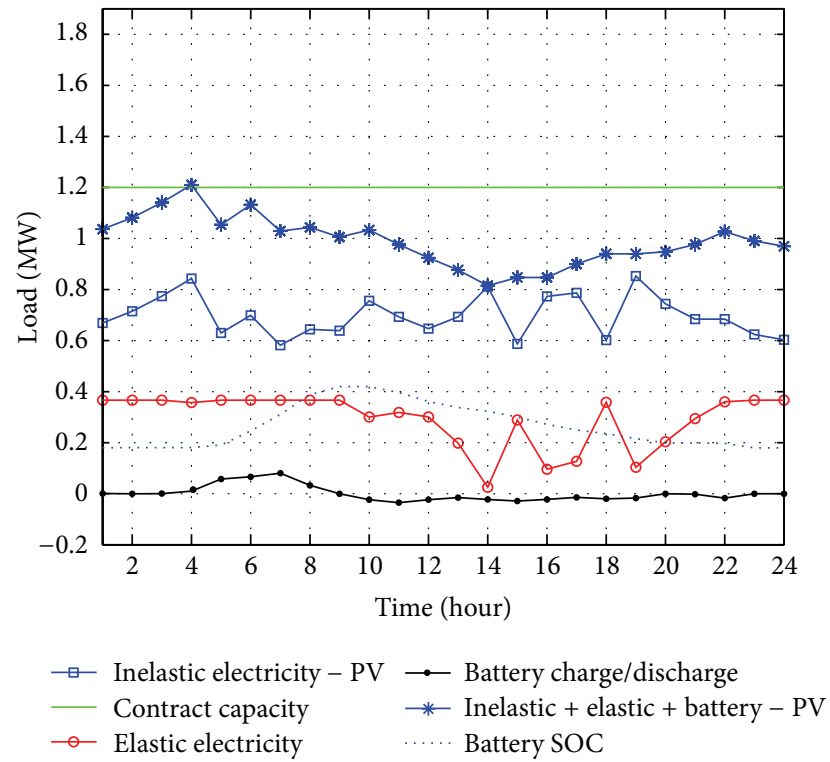

FIGURE 8: With GA to simulate customers' power use scheduling without battery set installed.

the contracted capacity even in periods of low price, such as the fourth hour, to avoid payment of the extra power fee.

\section{Discussion}

Table 5 compares the methods used and the simulated electricity price in various scenarios. The following conclusions are drawn.

(A) Customers' power use scheduling with the DR strategy reduces the electricity price.

(B) Both GA and IPM help customers optimally schedule their hourly power use to minimize the cost of electricity.

(C) Installing a battery saved about US\$34 in GA, and about US\$35 in the IPM. The battery charges off-peak as loading and supplies power during the peak period by discharging, which maximizes efficacy.

\section{Conclusion}

The work is concerned with optimizing customers' 24-hour power utilization scheduling. The considered optimization

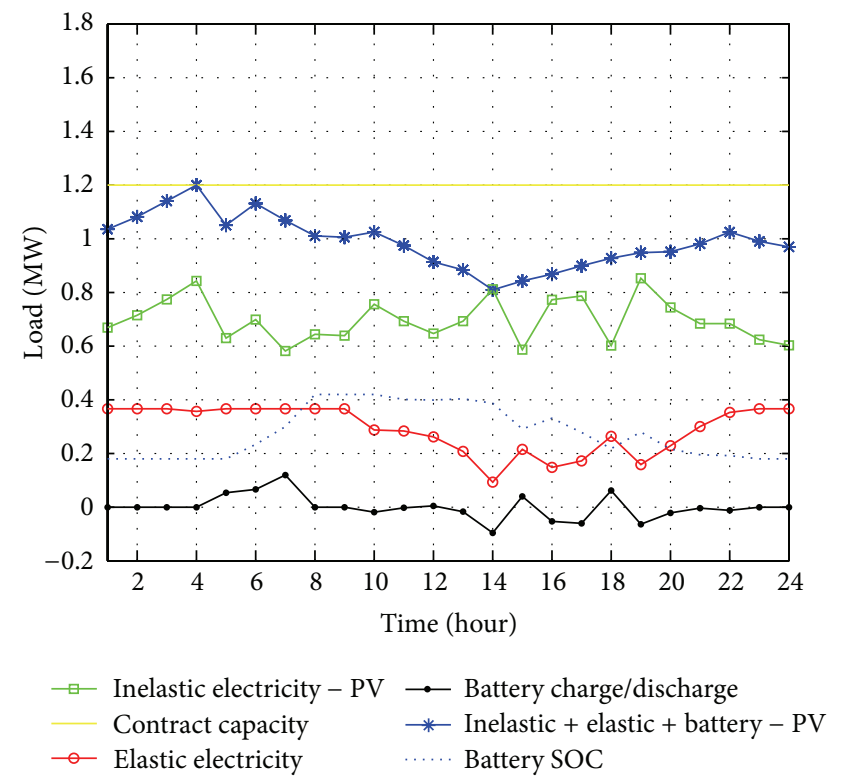

FIGURE 9: With IPM to simulate customers' power use scheduling with battery set installed and operating loss cost considered.

objectives are minimizing the electricity price and the battery cost, under limitation conditions. The interior point method and a genetic algorithm are used to simulate customers' 24hour power utilization scheduling.

The work proposes a new DR approach to smart home with PV generators and batteries, in which customers can control their power usage according to the cost of power that is announced by the power distribution company as an hourly electricity pricing curve. The electricity pricing information for power utilization scheduling is more abundant, so the proposed method provides more flexibility than other approaches in the literature, which provide only announced hourly electricity price. Simulation results reveal that the DR strategy for customers' power utilization scheduling reduces the total electricity price.

Adding batteries and considering the battery cost can reliably reduce electricity price, and the daily use is matched. Most importantly, the reliability of the power supply system can be enhanced, since when the supply and demand are unbalanced, the system can be forced to take power rationing measures, enabling customers to avoid some losses. 


\section{Conflict of Interests}

The authors declare that there is no conflict of interests regarding the publication of this paper.

\section{Acknowledgment}

This work was supported in part by the National Science Council in Taiwan, under the Project title: Caltech-Taiwan collaboration on energy research-uncertainty mitigation for renewable energy integration, Project no NSC 101-3113-P008-001.

\section{References}

[1] A. Ipakchi and F. Albuyeh, "Grid of the future," IEEE Power Energy Magazine, vol. 8, no. 4, pp. 52-62, 2009.

[2] P. Jazayeri, A. Schellenbery, W. D. Rosehart et al., "A survey of load control programs for price and system stability," IEEE Transactions on Power Systems, vol. 20, no. 3, pp. 1504-1509, 2005.

[3] S. Caron and G. Kesidis, "Incentive-based energy consumption scheduling algorithms for the smart grid," in Proceedings of the 1st IEEE International Conference on Smart Grid Communications, pp. 391-396, Gaithersburg, Md, USA, October 2010.

[4] M. H. Albadi and E. F. EI-Saadany, "A summary of demand response in electricity markets," Electric Power System Research, vol. 78, pp. 1989-1996, 2008.

[5] F. Ahmad, “The ethics of dynamic pricing," Electrical Journal, vol. 23, pp. 13-27, 2010.

[6] D. S. Kirschen, "Demand-side view of electricity markets," IEEE Transactions on Power Systems, vol. 18, no. 2, pp. 520-527, 2003.

[7] N. Ruiz, I. Cobelo, and J. Oyarzabal, "A direct load control model for virtual power plant management," IEEE Transactions on Power Systems, vol. 24, no. 2, pp. 959-966, 2009.

[8] J. W. Black and R. Tyagi, "Potential problems with large scale differential pricing programs," in Proceedings of the IEEE PES Transmission and Distribution Conference and Exposition, pp. 15, New Orleans, La, USA, April 2010.

[9] P. Palensky and D. Dietrich, "Demand side management: demand response, intelligent energy systems, and smart loads," IEEE Transactions on Industrial Informatics, vol. 7, no. 3, pp. 381388, 2011.

[10] S. C. Chen, K. M. Tsui, H. C. Wu, Y. Hou, Y. C. Wu, and F. F. $\mathrm{Wu}$, "Load/price forecasting and managing demand response for smart grids: methodologies and challenges," IEEE Signal Processing Magazine, vol. 29, pp. 68-85, 2012.

[11] A. Mohsenian-Rad, V. Wong, J. Jatskevich, R. Schober, and A. LeonGarcia, "Autonomous demand-side management based on game-theoretic energy consumption scheduling for the future smart grid," IEEE Transactions on Smart Grid, vol. 1, no. 3, pp. 320-331, 2010.

[12] Z. Wang and F. Li, "Developing trend of domestic electricity tariffs in Great Britain," in Proceedings of the 2nd IEEE PES International Conference and Exhibition on Innovative Smart Grid Technologies (ISGT Europe '11), pp. 1-5, Manchester, UK, December 2011.

[13] S. Braithwait, D. Hansen, and M. O'Sheasy, Retail Electricity Pricing and Rate Design in Evolving Markets, Edison Electric Institute, Washington, DC, USA, 2007.
[14] P. Yi, X. Dong, A. Iwayemi, C. Zhou, and S. Li, "Real-time opportunistic scheduling for residential demand response," IEEE Transactions on Smart Grid, vol. 4, no. 1, pp. 227-234, 2013.

[15] K. M. Tsui and S. C. Chen, "Demand response optimization for smart home scheduling under real-time pricing," IEEE Transactions on Smart Grid, vol. 3, no. 4, pp. 1812-1821, 2012.

[16] T. Cui, H. Goudarzi, S. Hatami, S. Nazarian, and M. Pedram, "Concurrent optimization of consumer's electrical energy bill and producer's power generation cost under a dynamic pricing model," in Proceedings of the IEEE PES Innovative Smart Grid Technologies, pp. 1-6, Washington, DC, USA, 2012.

[17] M. Pedrasa, T. Spooner, and I. MacGill, "Coordinated scheduling of residential distributed energy resources to optimize smart home energy services," IEEE Transactions on Smart Grid, vol. 1, no. 2, pp. 134-142, 2010.

[18] J.-Y. Moon, K. Shin, and J. Park, "Optimization of production scheduling with time-dependent and machine-dependent electricity cost for industrial energy efficiency," The International Journal of Advanced Manufacturing Technology, vol. 68, pp. 523535, 2013.

[19] P. Samadi, H. Mohsenian-Rad, R. Schober, V. Wong, and J. Jatskevich, "Optimal real-time pricing algorithm based on utility maximization for smart grid," in Proceedings of the 1st IEEE International Conference on Smart Grid Communications (SmartGridComm '10), pp. 415-420, Gaithersburg, Md, USA, October 2010.

[20] N. Li, L. Chen, and S. H. Low, "Optimal demand response based on utility maximization in power networks," in Proceedings of the IEEE Power and Energy Society General Meeting, pp. 1-8, San Diego, Calif, USA, July 2011.

[21] C. N. Kurucz and D. Brandt, "A linear programming model for reducing system peak through customer load control programs," IEEE Transactions on Power Systems, vol. 11, no. 4, pp. 1817-1824, 1996.

[22] N. Kah-Hoe and G. B. Sheblé, "Direct load control: a profitbased load management using linear programming," IEEE Transactions on Power Systems, vol. 13, no. 2, pp. 688-694, 1998.

[23] A. J. Conejo, J. M. Morales, and L. Baringo, "Real-time demand response model," IEEE Transactions on Smart Grid, vol. 1, no. 3, pp. 236-242, 2010.

[24] T. Hubert and S. Grijalva, "Modeling for residential electricity optimization in dynamic pricing environments," IEEE Transactions on Smart Grid, vol. 3, no. 4, pp. 2224-2231, 2012.

[25] H. Qian, J. Zhang, J. Lai, and W. Yu, "A high-efficiency gridtie battery energy storage system," IEEE Transactions on Power Electronics, vol. 26, no. 3, pp. 886-896, 2011.

[26] F. Fernandes, T. Sousa, M. Silva, H. Morais, Z. Vale, and P. Faria, "Genetic algorithm methodology applied to intelligent house control," in Proceedings of the IEEE Symposium on Computational Intelligence Applications in Smart Grid (CIASG '11), pp. 1-8, IEEE, Paris, France, April 2011.

[27] H. Hua Wei and S. J. Kubokawa, "An interior point nonlinear programming for optimal power flow problems with a novel data Structure," IEEE Transactions on Power Systems, vol. 13, no. 3, pp. 870-877, 1998.

[28] R. Marsten, R. Subramanian, M. Saltzman, I. Lustig, and D. Shanno, "Interior point methods for linear programming: just call Newton, Lagrange, and Fiacco and McCormick," The Practice of Mathematical Programming, vol. 20, no. 4, pp. 105116, 1990. 

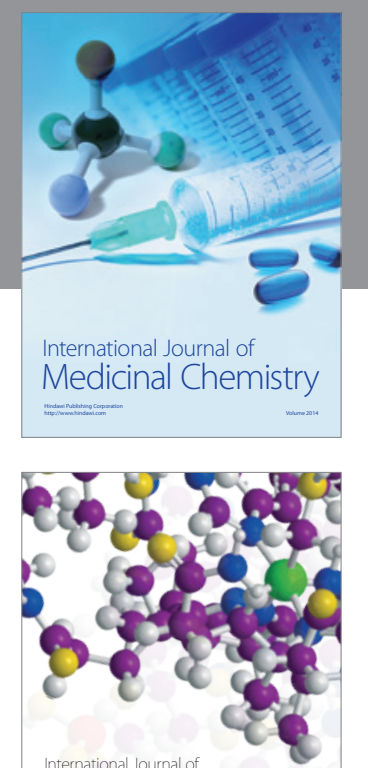

\section{Carbohydrate} Chemistry

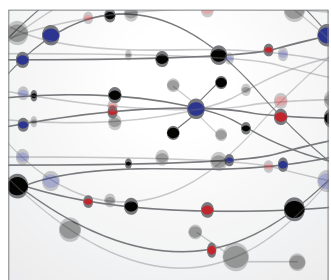

The Scientific World Journal
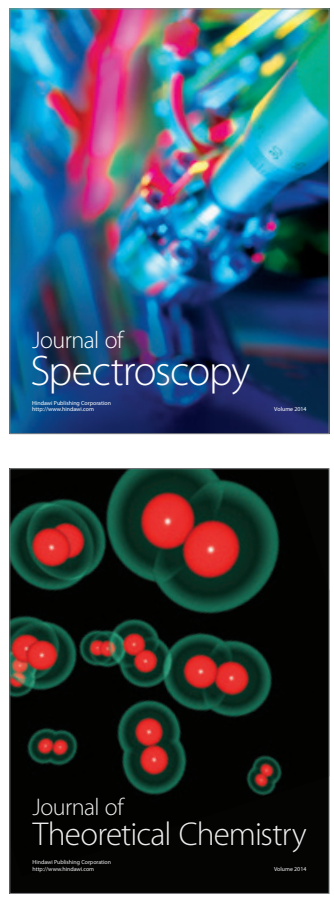
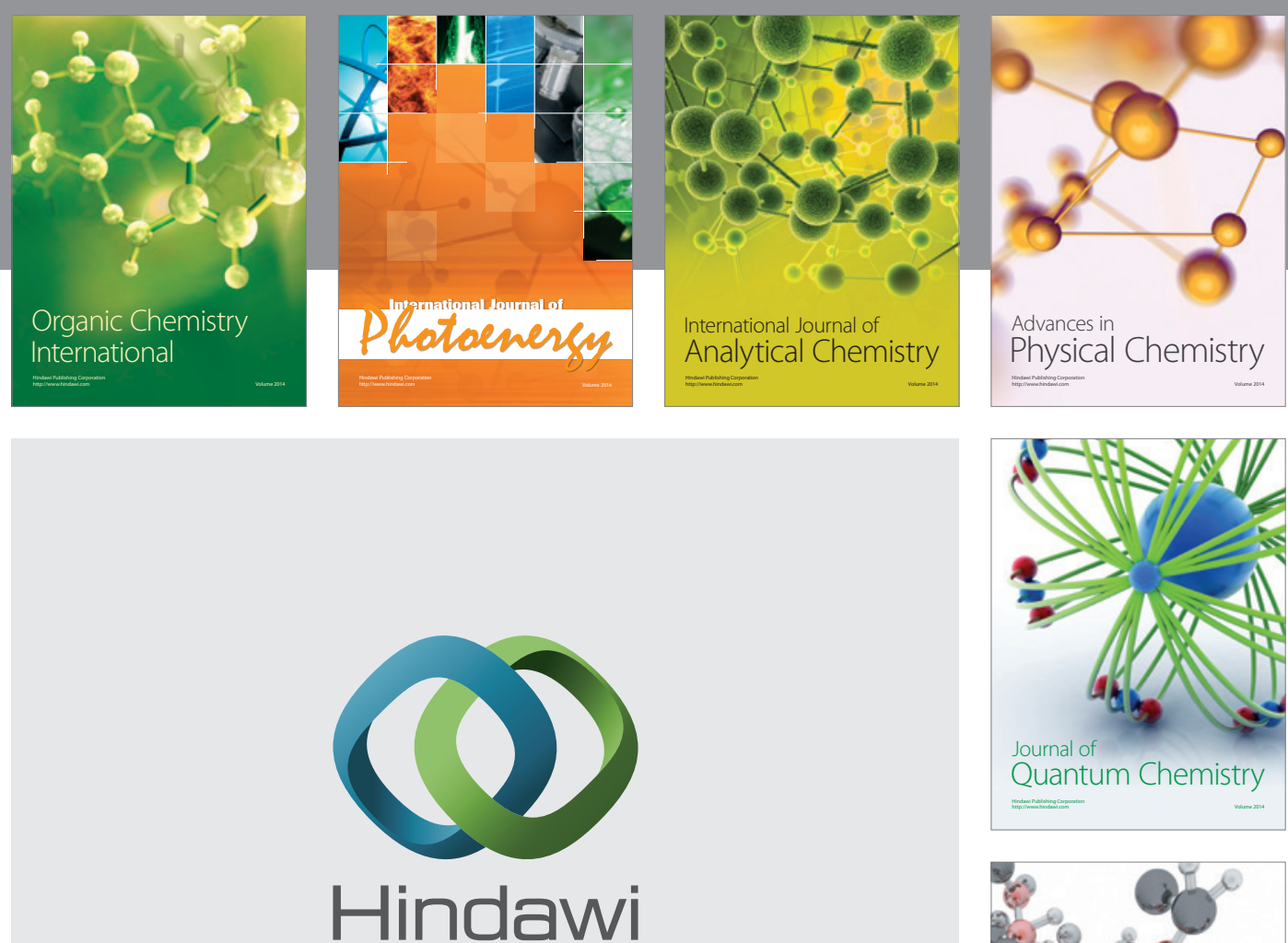

Submit your manuscripts at

http://www.hindawi.com

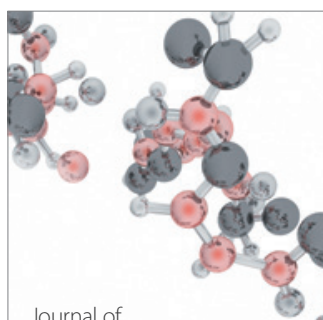

Analytical Methods

in Chemistry

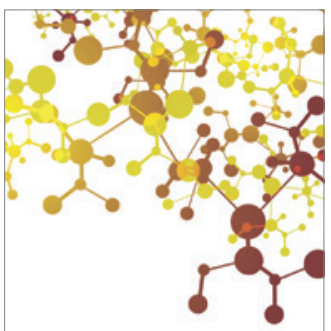

Journal of

Applied Chemistry

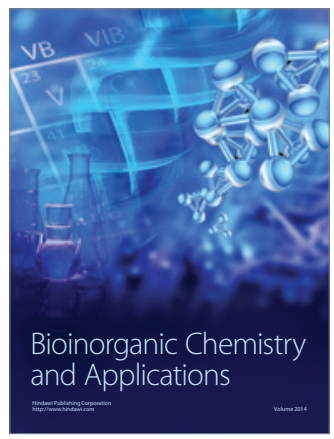

Inorganic Chemistry
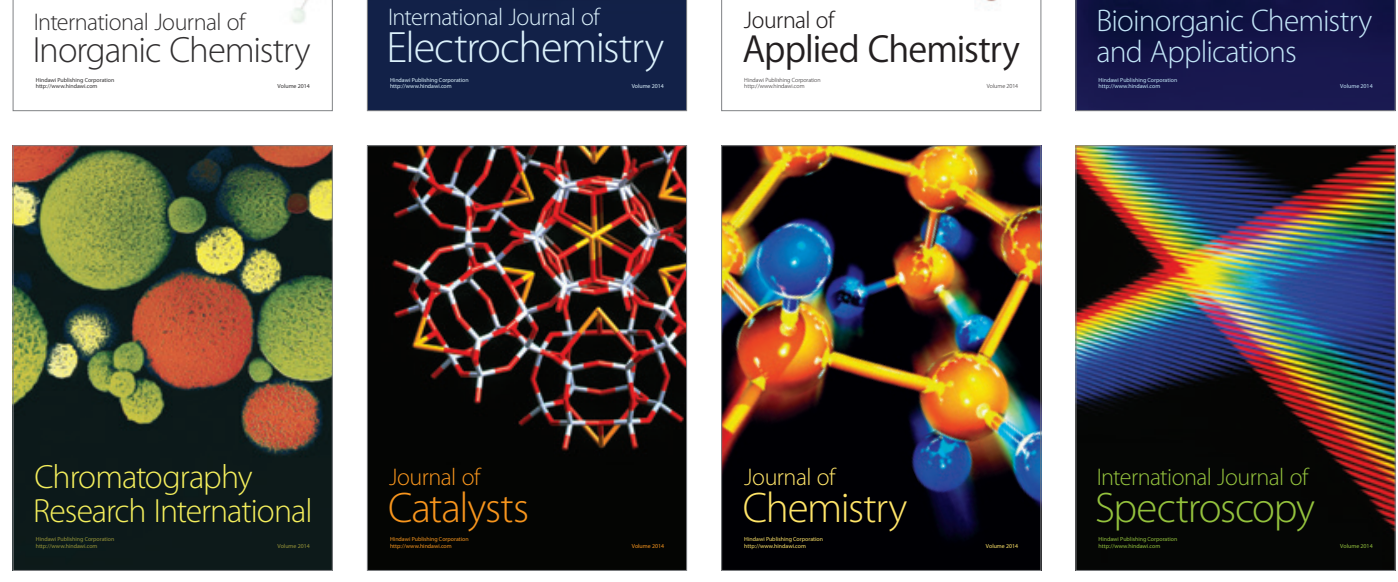